\title{
Working, living, and dying in Covid times: Perspectives from frontline residential adult social care workers in the UK
}

\begin{abstract}
Purpose

This article's core purpose is to explore 15 UK care workers' experiences during the Covid-19 pandemic.

\section{Design/methodology/approach}

The paper's 15 open-ended interviews with adult social care workers are complemented by digital ethnography in Covid-19 social media forums. This dataset is taken from a global mixed-methods study, involving over 2,000 participants from 59 different countries.
\end{abstract}

\section{Findings}

Workers reported a lack of planning, guidance and basic provisions including Personal Protective Equipment (PPE). Work intensification brought stress, workload pressure and mental health problems. Family difficulties and challenges of living through the pandemic, often related to government restrictions, intensified these working conditions with precarious living arrangements. The workers also relayed a myriad challenges for their residents in which, the circumstances appear to have exacerbated dementia and general health problems including dehydration, delirium and loneliness. While Covid-19 was seen as partially responsible for resident deaths, the sudden disruptions to daily life and prohibitions on family visits were identified as additional contributing factors in rapid and sudden decline.

\section{Originality}

The article offers revealing insights from frontline care home workers and thus provides an empirical snapshot during this unique phase in recent history. It also builds upon the preliminary/emerging qualitative research evidence on how the Covid-19 pandemic impacted care homes, care workers and the residents.

\section{Research limitations}

While the paper's sample cohort is small, given the significance of Covid-19 at this present time the findings shed important light on the care home experience as well as act as a baseline for future study.

\section{Social implications}

Care homes bore the brunt of illness and death during the first and second Covid-19 waves in the UK and many of the problems identified here have still yet to be actioned by the government. As we approach the summer months, an urgent review is required of what happened in care homes and this paper, we feel, could act as some part of that evidence gathering.

Keywords: Adult care home, Covid-19 pandemic, austerity, adult social care workers, death, dying. 


\section{Introduction}

The unanticipated and rapid spread of Covid-19 around the world in early 2020 compelled governments to implement public health measures in an attempt to curb infection rates and excess mortalities. While lockdowns, social distancing, curfews, and mask wearing seemed to be confined to the world of science fiction (Žižek, 2021), they quickly became a 'new normal' that many societies, including in the UK, implemented. Initially, governments argued these measures were partially enacted to ensure healthcare facilities, such as primary care and hospitals, were not overloaded with Covid-19 patients. However, questions regarding why healthcare systems were unprepared to deal with these challenges were not given much consideration in both mainstream media and political discussion. Rather, a concerted effort was made to alert the public to the very real risks posed by Covid-19, and to urge them to comply with public health measures to quell and control the transmission of the virus.

In the UK, the core governmental messaging was "stay at home, save lives, protect the NHS" and resulting campaigns also emerged such as the "clap for carers" initiative (Wood and Skeggs, 2020). The latter involved members of the public standing outside their houses at 8pm, making a collective salute to people working on the pandemic's frontline (Briggs et al., 2020). While this was initially directed towards NHS doctors and nurses and other related hospital/medical staff, its remit was widened to include adult social health care workers. Notwithstanding, staff working in care home residencies also deserved recognition, as they too were charged with saving lives. Given the elderly are the most vulnerable to respiratory illnesses (Oliver, 2020), as the UK braced itself for the virus, pledges were made by Prime Minister Boris Johnson along with various governmental health officials to ensure that elderly care home residents were appropriately shielded and protected (Daly, 2020).

Such pledges, however, did not manifest in the initial period or the Covid-19 'first wave' as basic public health protocols remained absent from care home strategy (Daly, 2020). Numerous commentaries and studies have since emerged highlighting inadequate governmental organisation and mobilisation of the care sector to limit the potential harm and death of elderly residents in both care homes and end-of-life care facilities (Amnesty International, 2020; Devi et al., 2020; Gordon et al., 2020; Henegan and Jefferson, 2020; McGilton et al., 2020). However, to date there is a dearth of qualitative accounts from frontline workers about what happened in care homes throughout the pandemic (for an exception see: Nyashanu, et al 2020).

Therefore, this paper explores some of the experiences of a small sample $(\mathrm{n}=15)$ of adult social care workers who lived and worked through this period. This data is also complemented by digital ethnography with care home workers in social media forums. Indeed, much of what the workers have to say requires situating within a constitutive context given that the sector was already experiencing various challenges as a result of neoliberal policy agendas. To begin then, this article situates care homes within a wider political context of privatisation and austerity. It then examines the political mismanagement of the virus in the care sector, laying the foundations for an overview of the global research study from where this sample is derived. The paper closes by shedding empirical light on what the care workers observed, how they felt, how it affected their personal lives, and emotional wellbeing. Accordingly, it is structured into three core themes: working, living, and dying in Covid-19 times. 


\section{Adult social care homes pre Covid-19 and the hangover from austerity}

While neoliberalism's tenets have been the subject of debate, there is a broad consensus that it has sought to embed market values such as competition, individualism, and privatisation into society's core (Slobodian, 2018). Based upon a belief that the private sector is more efficient, delivers a better-quality service and increases consumer choice, many public institutions that had historically been untouched by the market, including the National Health Service (NHS) and the Adult Social Care sector, have been subject to outsourcing over the last several decades (Pollock, 2005; Baines and Cunningham, 2015; Jones and Hameiri, 2021). From the 1980s onwards, state funding for Adult Social Care scaled back dramatically, ostensibly shifting emphasis from local authority provision towards individual and family 'choice' within a competitive market (Pollock, 2005; Fisher, 2021). The emergence of a private, for-profit sector coincided with the decline of state-provided care. Private provision now forms the "majority of residential and home care providers in England" (Shutes, 2012: 44).

In the aftermath of the 2008 global financial crisis, austerity measures were implemented in the UK, further consolidating the privatisation of the care sector. The 2014 Care Act governs the sector and the cost of care provision is largely borne by the resident although local authorities can cover some costs, following means-testing (Fisher, 2021). However, austerity cuts over the last decade have diminished local authority budgets leading to suggestions that the 'hollowed out' state passes costs onto the sovereign 'customer' who exercises freedom of choice in their care arrangements (Cunningham, 2016). The budget for Adult Social Care across all local authorities fell by 3\% between 2010-11 and 2018-19 while demand has continued to grow (Fisher, 2021). In the absence of adequate government funding, long-term care needs are increasingly left unmet with the cost of care, both in terms of financial support and unpaid caring responsibilities, falling on individuals and families (Fisher, 2021).

As most residents in care homes are over the age of 70, they often have complex health problems including dementia and emaciation thus making them more likely to die unexpectedly (Robbins, et al 2013). Nevertheless, these issues are compounded in the private care sector, since profitability is often prioritised over effective healthcare delivery (Baines and Cunningham, 2015). Punitive cuts to the welfare state, particularly to disability allowance, has meant that many vulnerable elderly people have been left with diminished social support; they are unable to access sufficient care and are dependent upon the assistance of family and friends (Power and Hall, 2018). Other research has found that many elderly people in care homes in the age of austerity did not receive regular visits from general practitioners (GPs), while care workers are often not medically trained and thus qualified to deliver quality healthcare (Robbins et al., 2013). With these issues in mind, many elderly people often "face a lonely and miserable old age" (Ferguson and Lavalette, 2013: 95), residing in under-resourced care homes. As we will show, this was very much compounded throughout the Covid-19 pandemic.

Working conditions in the UK's care sector under austerity were often degrading and poorly paid. Robbins et al (2013) suggest low morale amongst care workers is common, whereby attitudes of individualised responsibility prevailed over a team ethos. Others highlight how many private care homes employed migrants from Eastern Europe, maximising profitability for the private provider because they were hired cheaply through an agency on insecure and uncertain employment contracts (Shutes, 2012). Whilst they often possess little knowledge of their working rights and the UK's history of trade unionisation, they also work long and unsociable hours (Shutes, 2012). According to Costello et al (2020), care home staff in their study experienced an average lowlevel burnout but one-third of staff experienced high-level burnout. Whilst this was not connected to turnover rates, it was linked poor quality care. Turnover within the sector is extremely high and flat hierarchies limit the opportunities for advancement in an occupation characterised by the requirements of 'emotional work', demanding physical activity and intimate aspects of personal 
care (Fisher, 2021). Although these structural conditions left the care sector underprepared to deal with the virus, the subsequent governmental mismanagement compounded these issues, and most importantly, the distress of care workers and elderly people. It is to this systematic negligence that the paper now turns.

\section{Emergency policies, state failures and strategic mismanagement of Covid-19 in care homes}

As mentioned, elderly people in care homes often have complex health problems and one third of the care home population die each year (Oliver, 2020). There was always then a real risk that residential care homes were highly vulnerable to a new infectious disease. Whilst preventative policies could have been put in place to limit transmission and protect the elderly, this did not happen. Firstly, there was limited Covid-19 testing of both staff and residents meaning it was difficult to identify who was asymptomatic and who was positive (Bell et al., 2020) and there was also a lack of PPE to minimise virus transmission (Heneghan and Jefferson, 2020). The dearth of these provisions meant that the transfer of thousands of hospital patients to care homes often took place without both testing and appropriate measures in place, thus increasing the likelihood of Covid-19 infection (Devi et al., 2020). Since the objective was to free up bed space within hospitals in preparation for dealing with potential Covid-19 patients, the usual funding assessment protocols associated with care home placement were abandoned triggering an acceleration in discharges from these settings (Hanratty et al. 2020).

Curiously, the warmer winters over the previous years had seen a decrease in flu-related and respiratory-difficulties in the UK. For example, the ONS (2019) indicated that excess winter deaths were at their lowest in 2018 to 2019 with 23,200 in England and Wales, the lowest since the winter of 2013 to 2014 . This meant that people who perhaps would have died under normal meteorological winter circumstances did not. This reduction in demand led NHS trust managers, under pressure to look for places to make 'efficiency savings' (Carter, 2016), to cut services. Campbell wrote in November 2019 how " 17,000 beds have been cut from the 144,455 that existed in 2010 leaving only $127,225 " 1$. As a result,

The NHS entered the pandemic with one of the lowest numbers of acute beds per capita among developed nations and was already struggling to meet waiting time standards for emergency departments, surgery, or outpatients. (Oliver, 2020b)

The sudden rush to clear bed space in hospitals at the inception of the pandemic is attributable to diminished capacity. In addition, there was a lack of guidance on effective protocols which could have reduced the impact of the virus upon the care home resident population. This was reflected in the UK government's initial lack of discussion on care homes. In fact, the state's Scientific Advisory Group for Emergencies (SAGE) discussed care homes only twice in their meetings during the first five months of 2020 (Lintern, 2020) - as the first wave hit, peaked and diminished. Indeed, governmental pledges to 'shield' and protect the elderly and vulnerable from the virus did not fully materialise, as residents started to die in significant numbers. For example, between $2^{\text {nd }}$ March and $12^{\text {th }}$ June 2020, there were 66,112 deaths of care home residents in England and Wales, of which 19,394 (or 29\%) were officially attributed to Covid-19 (ONS, 2020). However, the attribution of these deaths directly to the virus has been questioned, largely because those dying with or from Covid-19 were not distinguished (Heneghan and Jefferson, 2020).

Relatedly, experts recognised that care home residents, who were also subject to lockdown and social distancing measures, were generally confined to their rooms which increased the chances

\footnotetext{
${ }^{1}$ See Campbell, D. (2019) 'Hospital beds at record low in England as NHS struggles with demand' in The Guardian, 25 ${ }^{\text {th }}$ November 2019, cited online on $16^{\text {th }}$ April 2021 at https://www.theguardian.com/politics/2019/nov/25/hospital-beds-at-record-low-in-england-as-nhsstruggles-with-demand
} 
of morbidity and raised safety and staffing concerns (Gordon et al., 2020). In the context of the public health restrictions on already-fragile care home residents, this meant that less contact with their families and carers equated to more deaths (Heneghan and Jefferson, 2020). What further complicated matters, as Gordon et al (2020:2) have suggested, is that Covid-19 amongst generally frail care home residents can result in the presentation of atypical symptoms:

COVID-19 frequently presents atypically in care home residents. Pyrexia, diarrhoea and delirium are common presentations, frequently in advance or absence of respiratory symptoms. Non-specific symptoms such as anorexia and decreased mobility may be the only presenting features but have next to no specificity for COVID-19, since they are common presentations of many illnesses in older people.

It was not until the summer months of 2020 that the government devised a full care home strategy (Daly, 2020; Devi et al. 2020), though they refused to publish detailed data of how care-home deaths from the preceding months had occurred (McNeil and McAskill, 2020). Prime Minister Boris Johnson was quoted as saying "too many care homes didn't really follow the procedures" (BBC, 2020) despite not having sufficient guidance or effective protocols. By July 2020, a national testing programme had been implemented in UK care homes, with weekly swabbing for staff and four-weekly swabbing for residents. Although decreased cases in the summer months were attributed to improvements in virus detection and prevention measures, residential care homes remained at significant risk of exposure to further outbreaks. As the second wave hit the UK, thousands of care home residents died once again (Jeffery-Smith et al. 2021).

There is evidence of anger among the care home workforce at tokenistic recognition of their efforts during the pandemic, such as 'clap for carers' and the provision of a green care badge (McGilton et al. 2020). A recent national survey conducted among care workers $(\mathrm{N}=1194)$ found that they felt stigmatised, lonely, unsupported by management and lacked support during these waves of Covid-19 infection (Greene et al., 2021). It is within this context that we situate our findings. First we briefly turn to the methodology before presenting our data.

\section{Methodology}

Both the care worker interviews and Facebook forum data in this paper are taken from a wider multi-phase mixed-methods project. The aim of the study was to capture people's experiences of and feelings about the pandemic as it unfolded. In line with Rhodes and Lancaster's (2020) suggestion that public health emergencies should be studied as they unfold, we set out in March 2020 to capture this epochal event as it progressed. We adapted our methodological approach according to each new phase in the pandemic. The project's three key phases so far include:

1. Lockdown. Approximately March - May 2020

2. 'New normal'. Approximately June - September 2020

3. 'Viral hiatus'. Approximately October 2020 to March 2021

We adapted our approach to the realities of lockdown and social distancing and were able to use a range of quantitative and (distanced) qualitative methods. The first phase included an online survey which was promoted primarily on Facebook and LinkedIn, receiving 985 responses from 59 countries. This survey was designed to capture personal circumstances and experiences of lockdown and the pandemic, including work and employment, attitudes towards government measures, hopes and fears for the future. Online surveys have significant scope and reach (Briggs et al., 2020), evidenced by both the response rate and range of countries we managed to cover.

This was supplemented with over 40 hours of digital ethnography, primarily on Facebook forums in coronavirus discussion groups to gather sentiments and feelings. We acknowledge that such forums bring with them dilemmas (Leigh, 2018) but, subject to restrictions ourselves, we had to 
rely on these as a means of data collection. Data deriving from these forums normally followed the completion of our survey. Where participants had doubts or even wanted to add more context to their responses, they added additional comments. We responded but frequently the same time, others, having seen the discussion, entered into the forum exchanges. They had not only seen the fact that we were undertaking a study but were also keen to voice their experiences and concerns about what they had experienced.

Phase 2 occurred as countries emerged from the initial lockdowns and prompted a new survey to capture the evolving social changes wrought by a 'new normal' of face masks, social distancing, and restrictions imposed upon cultural freedoms. This survey received 540 responses from 40 different countries. The digital ethnography continued to bolster themes from the semi-structured survey. Moreover, the lead researcher conducted 16 online semi-structured interviews with survey respondents to probe deeper and elicit more nuance.

As the autumn saw a sharp increase in cases, hospitalisations and deaths, with governments responding with tighter restrictions, we moved into phase 3 . This involved a third semi-structured survey which was circulated online to capture feelings and experiences of the 'viral hiatus', particularly with the resumption of national lockdowns during the winter in several countries. This survey generated 407 responses from 33 countries. Phase 3 also included over 80 hours of digital ethnography and 30 semi-structured online interviews to test our emerging findings in a more detailed manner.

Ultimately, this project was conceived with flexibility in mind and has adapted to the changing picture both in the UK and across the world. The range of data is vast and through analysis of survey responses, digital ethnography, and semi-structured interviews, it became clear that a subsection of our survey samples from the three phases included data which contained themes pertinent to UK residential care home workers. Moreover, throughout the fieldwork, and because care homes have continued to be a neglected for analysis, we reallocated our time to work up a convenience sample based on responses to our generic pandemic surveys and requests for interviews in Facebook forums where we had been doing our digital ethnography, gained the trust of many members and had spoken with frontline staff. As we had done with the three phases of the survey research, we generated a call for potential participants to speak about their experiences of living and working in care homes and generated this paper's sample of 15 UK adult social care workers. All the names that appear in the remainder of this article are pseudonyms and any potentially identifiable information has been removed to ensure anonymity for our participants. We have been able to identify the themes and data set out below which capture the experiences of these care workers since the onset of the pandemic. As we will see, they also possibly raise further questions about governmental mismanagement, working conditions, personal feelings, and emotions during the Covid-19 pandemic.

\section{Working}

Our sample of care workers recognised that the residential care sector was a low-paid industry and felt that it had been neglected by government and placed under further pressure by austerity measures. Despite feeling the moral reward of "helping other humans", as one of our respondents Laura said, some of the older members of our small sample recognised that over the last ten years their workloads had increased while their pay had remained the same. For this reason, Donna reflected that "you get a high turnover, many people come and go, lots of agency staff". Furthermore, Carmen - an experienced carer in her mid-50s - recalled how prior to the pandemic it had become an industry which proved difficult to retain staff, hence the high turnover and reliance on agency staff: 
We couldn't get people to stay. Before, years ago, there were many more staff, and they could spend more time with the residents. Now they cut all the staff and we are doing more, cleaning, doing the beds, less time with the residents.

Indeed, most participants concurred that the advent of Covid-19 exposed many flaws; not only in government policy but also operational defects which, at the time of the first wave in March 2020, did more detriment than good. The unanimous criticism was that lockdown was not implemented quickly enough, allowing the virus to spread in the community. At the time, midway through March 2020, airports remained open. Helen, an experienced carer in her 50s, said:

We should have closed borders/travel ASAP knowing that cases were coming in and the government didn't take the threat seriously or soon enough and certainly did not put us in lockdown soon enough. We should have ordered PPE in January when we heard about Covid.

As previously stated, SAGE did not appear to be focused on implications for the care home sector and safety protocols were largely absent during the first wave. Carmen added this about the first wave:

During the first lockdown, we had people coming in from hospitals without being tested for Covid. The government didn't care. Why have they got to then be isolated for 14 days? They didn't know. Do they have Covid? They didn't know. We have to be PPE'd up, go over and deal with them as well as our guys. They wanted everyone out of the hospitals to free it up for Covid. We were fighting to keep it out and the government were putting them into our home!

In the early stages of the pandemic, much of the sample reported not having sufficient access to PPE while protocols for staff absences had not been planned. This conversation at the beginning of April 2020 between Lisa and Fiona, a care home cleaner and unit manager respectively from the north of England, highlighted these concerns at the height of the first Covid-19 wave:

Fiona: I clean in a care home. I have been off with a bad back but am due back on Saturday. Apparently, we have six new residents who have come from different hospitals to free up space. They are being monitored for seven days to see if they show signs of Covid. The manager says we do not need to wear face masks as it will worry the residents. I am so worried for my family if I bring anything back. We will wear gloves and a flimsy apron. I'm so anxious...My co-worker messaged me and told me this. She also asked me what am I exactly worried about as the residents' temperatures are taken twice a day. But I'm worried coz any staff member can bring it in and spread it!! Also these residents might show symptoms in a couple of weeks? I'm going in to see what it's like and if I can't wear a mask then I will walk out.

Lisa: We have new residents that have been brought in from hospital to make room in the hospitals for Covid. And aside from the residents it's hard to keep a distance from other staff!! I think we should all wear them. So many people I know who work in care homes being told they can't wear masks.

Fiona: Really? It's crazy!

Lisa: Yes told its non-essential. I was furious when told a good friend of mine is worried sick and doesn't want to go to work.

Fiona: Is she going to go in? I really don't want to. I'm so anxious.

Sharon, a care home manager, elaborated further in the discussion: 
Sharon: I manage a home, PPE is in short supply from all of our usual suppliers, the government gave us 300 masks. Homes can only create policies from guidance (I personally received info re PPE yesterday) we are wearing masks but it will also depend on the size of the staff team and how much PPE is needed daily, but when it runs out where do homes get more stock from? So this is a worry - no stock = no wearing of PPE.

Fiona: So will we be at risk if we don't wear them?

Sharon: I made the decision for our staff to wear them 3 weeks ago without any guidance because I believe the risk would be higher without PPE, you also have to take into account the type of care setting \& the risks of each individual service user but it doesn't solve the problem of PPE being out of stock -2

Pressure to discharge patients from hospitals to generate bed space heightened anxiety levels among our small sample not only because they feared bringing the virus into the care home, but also contracting it themselves. Debbie said this early into the first wave:

Debbie: Until yesterday [ $3^{\text {rd }}$ April 2020] they were refused to be allowed to wear face masks even if they had their own. The residents were also allowed to move freely around the care home, when they've had residents in and out visiting hospital. Since yesterday they're finally allowed to wear masks and the residents aren't allowed out of their rooms because some residents have developed a cough $\mathrm{B} \&$ but they're just the flimsy thin ones. She asked if she could bring her own one (with a filter) and they said no as they don't want to worry the residents

The seeming lack of clarity around appropriate safety measures described by Debbie had consequences for a few of our participants who were adult social care agency staff. After seeking clarity on mask wearing at the height of the first wave, Linda was not paid:

Linda: Is it important to wear a mask and PPE? I am a care worker, I work for an agency, and I am worried. On the $3^{\text {rd }}$ April I was temporarily put charge of a care home in [place], many residents were poorly and I asked for a mask to protect myself. The nurse told me I have provide myself with a mask then I went to the reception to ask for a mask. After an hour a lady brought a mask, also I ask her to bring them for the other staff a mask and she told me she don't have another. When the manager arrived, that lady reported me to the manager. The manager intimidated the staff, she was rude with me only because I asked for a mask and she asked me to go home. Only because I asked for a mask? I explained to her what the risk is to be exposed to work without mask in that place. Also, she refused to sign my timesheet and I guess now I lose my job. Many people don't realise the risks of Coronavirus, not only at the workplace but also in our community. I am very frightened to be infected and I realise nobody care to protect medical staff. I tried to call at CLINICAL COMMISSION GROUP and someone guide me to NHS, I call at NHS and same situation someone guide me to call at CQC. CQC told me if I need any prescription or PPE I can order online to buy.

Some respondents felt that it was just a matter of time before staff would also contract the virus. As staff started to test positive and/or self-isolate because of Covid-19 symptoms, residential care home staff numbers depleted significantly which put additional stress on some of our sample when there was no one to replace them. In one situation, as the second Covid-19 wave took hold, Rebecca was one of five workers faced with caring for 34 residents. She was compelled to move and thus live in the care home as she attempted to provide as much support as possible:

Rebecca: The worst thing was it felt there was nowhere safe to have our food. We were dehydrated. We couldn't just quickly take our mask off, you can't do that. In the care 
home, there is carpet everywhere, it's not a sterile environment, it was bedding, curtains, and some of the patients had dementia and were wondering around. They had lost their routine and we couldn't keep them in their rooms. Others [residents] were distressed because they couldn't see families and we had to take them back to their room. One patient pulled the visor and mask off me. It was inevitable.

Under normal circumstances, the workforce would have been 31 but 26, including the cook and cleaner, had either contracted the virus or were self-isolating. Rebecca noted how "Public Health England never sent anyone else, no one came". Despite the goodwill of the other inexperienced staff, she was left asking herself how it had come to this:

Rebecca: When I got there, I was nervous, we had trained a lot for Covid and almost all of the residents were positive from PCR. When the gates opened though, no one was there. I imagined there to be infection control or some sort of order, here is the person in charge of PPE but there wasn't anyone. We were all just guessing. Public Health England were saying make sure there is a staff area which is clean but it was impossible. All the staff had left. I was thinking why don't they just stay there if they were infected but all were poorly and symptomatic and I remember thinking but since I had it I think everyone must have been properly ill. We were doing ward rounds and showing the doctors the patients from our phones. No medical professionals came in. No one to do Covid tests. No one could come in and get these people on fluids or anything. And there were a few carers there who had no experience, one was a council worker but she had no experience. Two agency workers but they lacked experience. We should have asked more questions at the time.

Experiences such as these heightened anxiety levels which were exacerbated by the possibility of contracting Covid and passing it on to other loved ones. Indeed, the families attached to these care home workers were equally put under pressure.

\section{Living}

Working pressures for some of these carers were intensified by complex personal circumstances. At the start of the first lockdown, Elsa was working 16 hours a week in a care home. She described the experience as "traumatic" because "there was so much panic around the measures and if we were able to adhere to them, if we had enough PPE and managing the depression of the residents because they couldn't see their families". However, many educational institutions during the lockdown were closed including the one her daughter attended daily. When the nursery closed, Elsa's tax credits were stopped. Her request for furlough payments was also denied. She had to rely on her mum to care for her daughter; but many friends refused because of the public health measures which curtailed households from meeting. However, her mum contracted the virus and self-isolated for several weeks. Therefore, Elsa was forced to take time off work, time for which she was told she would not be paid and got into debt with the landlord. Elsa claimed "My hair started to fall out" due to stress. Eventually, her sister took time off from her job, three hours away, and came to stay with Elsa and care for her daughter, though she reported being "stressed, 24/7”.

The requirement to work longer hours, as other care workers went off sick or under instruction to self-isolate, meant that family life became increasingly compromised. This was the case for Rebecca - a care worker who "couldn't say goodbye" to her own mum in another care home when she "died with Covid". Rebecca had already experienced significant stress and anxiety, having been one of five staff responsible for 31 residents but late in 2020 she tested positive for Covid19: 
Rebecca: When I left [because of a positive Covid test] I tried to switch off, I didn't even want to be a worker anymore. I wanted to forget about it and didn't want to speak to anyone about it. Then I had to self-isolate here. I have a husband and four kids so he would just leave me in the room, leave my food outside and I had to stay in the room for 10 days. I was crying and was very emotional. Now I am in the room by myself, can't get a cuddle or any support from my family.

Donna, already working "a lot of overtime" above her 25-hour contract, described the additional stress of restrictions applied in schools during the second wave. Her young son struggled with the sudden changes:

Donna: We are adults, we can adapt but my 8-year-old has struggled with it as he doesn't understand why suddenly there are so many rules in school and he is playing up now, started getting in trouble. I've been called to meetings in school but can't make them because of work.

During the "second or third" Covid-19 wave at the beginning of 2021, Carmen found herself in an almost impossible situation; she had to work, home-school her children and support her elderly parents:

Carmen: When the second or third wave whatever it was, they got it in one wing so we shut that down. Staff had to wash hands, gloves, temperature taking and it was quick. We didn't get Covid until October or even November 2020. It was hard as I was homeschooling, the kids stayed at home, I was going out to the shops and doing work, and it was hard as I am a single mum. No one was out. I couldn't see my mum who has Alzheimer's and lives with my dad. That was difficult.

As the second UK lockdown continued, there were further unintended consequences for her eldest daughter who tried to take her own life:

Carmen: As a family thing, my daughter took a turn for the worst as she has mental health problems and she couldn't be left alone. She is 16 and has always had depression but lockdown made it a lot worse. She had too much. Like a lot of children her age, lockdown has done damage to them. My daughter took an overdose while I was at work during the Covid in January so I rang her and paramedics answered. I had to take time off work but my colleagues helped me through it.

Like Elsa, Carmen's leave was unpaid and she felt that had it not been for the emotional and psychological support of her colleagues, it would have been much more difficult. Indeed, these pressures were further exacerbated by the high probability of infection and increased levels of death that often surrounded them.

\section{Dying}

While there were numerous criticisms levelled at the UK government and respective healthcare institutions, such as Public Health England, participants unanimously critiqued the use of blanket Do Not Resuscitate (DNRs) policies. Some of our sample said that doctors and GPs were issuing DNRs without the consent of the patients or their families meaning that if they were ill, they would not be taken to hospital for life-saving care. For example, Sarah, who only entered the care sector in August 2020 because she was made redundant from an admin job at the start of the first lockdown, was "deeply affected" by this. Towards the latter stages of 2020, during the second 
wave, she had observed that this practice was still being used - despite being under investigation from the Care Quality Commission ${ }^{2}$ :

Sarah: There were people coming in from hospital that said 'Do Not Resuscitate' but there was nothing in the box which would say if the family had been contacted or it had been discussed with them. The hospitals were just putting DNR on these patients because they wanted to clear the beds in the NHS. The senior was then charged with phoning these families and telling them. The families were turning up and crying outside and they couldn't come in because of social distancing. It should be agreed by the families and the doctors should consult them but it was all being done behind their backs as these people have dementia and things. That for me was very sinister, this was not right. I have had to keep quiet and it breaks me every day. We had 17 come in for respite from hospital in October and November and they are all DNR on them. They all died.

Furthermore, there was no suggestion that these 17 residents had Covid. Donna also noticed how DNRs were irregularly assigned "people were having DNRs on their files against their will. They were doing it to everyone, even to disabled people, younger people with severe disabilities" she said. Sarah continued:

Sarah: At Christmas, there were five residents in hospital, not Covid related because they are old and ill anyway and they all had DNR on them and they never returned. None of them came back. They all died. None had Covid. Not these five or the other 17 before December 2020. They were tested every three days for Covid in the home and they always came back negative [voice quivers]. These people were all in their $80 \mathrm{~s}$, the residents were fine as I worked Christmas and Boxing Day with them, then all five suddenly went into hospital on the 27th and didn't come back.

Moreover, Sarah relayed how the first wave did not really impact upon the care home but, with the advent of new public health measures like social distancing which changed the delivery of care practice and banned families from physical visits, this significantly weakened the residents:

Carmen: It wasn't all down to Covid though [dying]. It was more that the families that couldn't come in. When they stopped, that's when our residents went downhill. That was heart-breaking. You knew that link had gone. I had an elderly woman who was very loved and had visits from family who came up every week, drove 130 miles, but when they stopped coming you could see it in her eyes and body language. She went downhill quick because the connection, they didn't want to eat or drink, they became weak. Once Covid come in it just took them out, one then two a day. They were already weak, they had given up many of them. I could see them wanting their family. There was nothing we could do, we put the music on, you knew they were going to die with a broken heart. The zoom calls but they didn't understand, there was no physical presence. Other times there were maybe visits in a tent outside but they didn't recognise their family as they had masks on, white suits, and they didn't understand.

Carmen had watched the mental and physical health of the residents disintegrate because of social distancing over the first wave and suggested that this made "their immune system so low because when flu comes it can do the same. I have seen that from some who passed away that they put

\footnotetext{
${ }^{2}$ See Booth, R. (2020) 'Inquiry begins into blanket use in England of 'Do Not Resusitate' orders' in The Guardian, $12^{\text {th }}$ October 2020, cited online on $12^{\text {th }}$ April 2021 at https://www.theguardian.com/world/2020/oct/12/inquiry-begins-into-blanket-use-in-england-of-coviddo-not-resuscitate-orders
} 
Covid on their death certificates but they had not been tested." Donna reported similarly early in 2021:

Donna: That happened all the time, writing Covid on death certificates. We did lose one lady, so old, obese, very ill she was dying anyway, we expected her to die soon. She was in and out of hospital. She was rushed into hospital, got a Covid test and no one knew what happened as she died. They said she died of Covid, it was on the death certificate, but she was so ill, she was on the way out before Covid came along. So we can't say they died of Covid, can we.

When the second wave hit later over the course of autumn/winter 2020 and early 2021, most of our participants felt that the already weakened and disheartened residents died without a fight. Like Sarah, who said her residents "didn't understand social distancing and got upset when they couldn't see family", Debbie too felt "it was awful not letting family visit their loved ones. We could see the sadness of our residents, even more heartbreaking knowing they don't have a long life left...I mean it's probably one reason why they gave up and died". For this reason, most of our small sample were not totally convinced it was Covid that killed their residents. Reflecting on the whole experience, Charlotte said "they [the residents] should have had chance to see their families. Instead, their dementia got worse due to no visits and deaths rose." Relatedly, Carmen suggested the residents:

...were going downhill before Covid because they didn't have that bond. We tried to explain about the virus but they didn't understand and they were so confused.

Similarly, Rebecca could not distinguish how many residents died of dehydration, loneliness, Covid, or a combination:

Rebecca: It was inevitable some would die. When I went in, some were coughing, they weren't eating, they were unwell. It was scary looking in all these rooms and they all have these symptoms, coughing, hacking up, sneezing, and I was thinking 'shit' and it had been in the media about the virus and now I am here in the home and everyone has got it and I am here. It was an adrenalin rush. You can't get the meds to them as they were coughing so much and they were dehydrated so they couldn't take their tablets. We couldn't get their food or meds on time to them so they went downhill. It was awful. Sometimes I still think about it at night, and I am walking through those corridors and I am thinking I don't know where to start.

\section{The future}

Placed in this context, ten of the 15 carers we spoke to said their experiences during the pandemic had left lasting mental health problems while eight of the 15 carers we spoke with said they couldn't see their future in the industry. Sonya, a carer from the south of England said: "Most of us came into this profession to care for the elderly with love and compassion and it was drastically restricted with huge effect. I don't know if I can continue working here'. Others spoke of a feeling of persistent anxiety:

Rebecca: I am struggling a lot with anxiety, I feel sometimes that I could have done more. I get angry. I mean why didn't anyone come and help? Why were we left in that situation? It is an experience I guess. I don't know if I want to continue in the job. I feel unsettled and hard to engage with my life. Sometimes I feel I am with them but other times I feel my head is somewhere else. Say I am at dinner, I am not engaging with what they are talking about. 
Sarah: I have really struggled with it. I have horrible thoughts. I need to leave my job, I can't be a carer. It haunts me. I have even been down to the train tracks, I have thought about suicide.

To date Sarah has found another admin job while, as we conclude this paper, Rebecca has just handed her notice in. Agnieska, a care worker who had initially come from Poland, also reported leaving the profession:

Agnieska: I'm a care worker. I worked in care homes. When I saw what's going on, I resigned ...I was fed up with weekly test, with wearing masks during 12 hours shifts (I had problems with my breathing), I was fed up to see residents locked down in care homes. Enough was enough! I went back to Poland.

\section{Discussion}

The Covid-19 pandemic has caused myriad social distress, not least because of the increase in mental ill health and excess mortalities (Briggs, et al 2020). One of area where this distress has been most acutely felt is the private care sector where profit is often put before the needs of both workers and elderly residents (Baines and Cunningham, 2015; Ferguson and Lavalette, 2013). Indeed, the Conservative government's rhetoric of appreciating care workers - who have been rebranded as key workers throughout the pandemic - principally manifested in community initiatives like 'clap for carers' and the green carers badge, contrasts sharply with the data presented in this paper from frontline care workers.

Working throughout the pandemic has been both emotionally and psychologically exhausting for our research participants. Qualitative research with care workers in many UK private care homes ascertained that they were fearful of infection due to the lack of PPE (Nyashanu, et al 2020); a finding consistent with the experiences of our participants. According to Jones and Hameiri (2021), the initial dearth of PPE exposes flaws in neoliberalism and its inability to deal with social problems, partially because of the marketisation and fragmentation of services like much of the care sector. This meant private providers secured PPE from overseas and focussed on short-term gains, making supplies vulnerable to the disruption of global supply chains (Amnesty International, 2020). Understandably, this shortage generated increased worries about the virus in our research, particularly in terms of getting infected and transmitting the virus to loved ones and vulnerable elderly residents. Poor management of the virus engendered stress and anxiety, compounding already existing feelings that they were undervalued and underappreciated. Many expressed worries about being unable to adequately protect those in the final stages of their lives as the implementation of support and measures specifically for the care home sector was "slow, late and inadequate" (Daly, 2020: 996).

Elderly residents in care homes with dementia are at an increased risk of distress during the pandemic (Brown, et al 2020), not least because it has exacerbated their state of confusion. Frontline care workers in this research spoke about how it was profoundly distressing to witness elderly people, particularly with dementia, unable to see their loved ones, fomenting feelings of helplessness and despair. They suggested some residents had lost their sense of social purpose, were deprived of hope, and they passed away with a broken heart. The use of blanket DNR orders during the first wave of the pandemic to free up hospital space (Amnesty International, 2020) currently under investigation by the Care Quality Commission (Booth, 2020) - was a point of concern for the participants, suggesting the deceased family's consent was occasionally not secured. DNR orders have been met with fierce criticism, arguing that they are ethically problematic as they fail to protect the rights, dignity, and value of the individual (Bledsoe et al., 2020). Equally, references to the application of Covid-19 to death certificates drew questions. In consequence, they propagate the belief that 'some lives are valued more than others' (Bledsoe et 
al., 2020), potentially serving to mask a care system that was ill-prepared to deal with the pandemic. Placed in this context, many of our research respondents wanted to leave the profession; the damage caused by working through the Covid-19 pandemic had become too difficult to subjectively fathom.

Working long and unsociable hours and often under intense pressure, many of our respondents reported experiencing emotional instability. Some reported crying on a regular basis, feeling a sense of guilt that they were unable to adequately protect and help elderly residents. Our data indicate that our participants were heavily burdened by the governmental failures that have become increasingly characteristic of neoliberal states and which have been laid bare by the Covid-19 pandemic (Daly, 2020; Jones and Hameiri, 2021; Saad-Filho, 2020; Schwab and Malleret, 2020). Indeed, as Jones and Hameiri (2021:21) have recently argued, the pandemic has provided yet further evidence that neoliberal states "have clearly become dysfunctional for solving very basic social problems". An issue exacerbated by neoliberalism's assault upon collectivised institutions and worker's unions. For Streeck (2016: 37), the result for individual citizens is,

...an under-institutionalised way of life...always at risk of being upset by surprise events and unpredictable disturbances and dependent on individuals' resourcefulness...

In essence, individual citizens experience less protection from structural forces and crises. They are expected to become 'resilient' and respond to and manage these by drawing upon their own personal resources (Streeck, 2016). Neoliberalism has shifted responsibility away from 'hollowed out' state institutions and towards a system of diffused regulatory governance that relies upon efficient functioning markets and supply chains of which government retains 'oversight' (Jones and Hameri, 2021). However, in its current post-crash state, neoliberalism is in perpetual crisis, continually kicking problems down the road (Streeck, 2016; Harvey, 2010). An unbalanced, unstable economic system and an increasingly under-institutionalised society were ill-prepared for a global pandemic and this had profound consequences, including for care workers. The feelings of uncertainty and instability generated in the absence of adequate protections for our sample were intensified by the impact upon the mental health of some of their children. It seems that the pandemic and associated failures of governance, have led to the exacerbation of more precarious conditions within this branch of the care sector more broadly (Daly, 2020; Davis, et al 2015).

The, so far, successful distribution of approved Covid-19 vaccines within the UK will hopefully lessen the impact and severity of future waves of infection, particularly during the winter months of 2021 and 2022. There is, however, potential danger should the various issues outlined in this article remain un-addressed. As we have outlined, the evidence points strongly towards the slow diminishment of the adult care sector in the recent period and the growing precarity of its workforce even prior to the pandemic. As our data indicates, the impact of the Covid-19 pandemic upon an already under-resourced sector and its workers has proved devastating; and the experiences of our, albeit small, sample of participants is further evidence of this. The personal resilience of beleaguered staff and residents has suffered with each wave of the virus and each round of government intervention. The cumulative weight on their shoulders has manifested in heightened levels of stress, anxiety, trauma and death. Our data suggests that facile blandishments and tokenistic gestures are inadequate substitutes for a fundamental reconsideration of the core issues at the heart of the care sector, both in terms of its structure of provision and conditions of employment. 


\section{References}

Amnesty International (2020) As If Expendable: The UK Government's Failure to Protect Older People in Care Homes During the Covid-19 Pandemic.

Baines, D \& Cunningham, I (2015) Care work in the context of austerity. Competition \& Change. 19(3): 183-193.

BBC (2020) 'Coronavirus: Boris Johnson criticised over 'cowardly' care home comments', $7^{\text {th }}$ July 2020, cited online at https://www.bbc.com/news/uk-politics-53315178

Bledsoe, T Joela, J Deep, D \& Sulmasy, L (2020) Universal Do-Not-Resuscitate Orders, Social Worth, and Life-Years: Opposing Discriminatory Approaches to the Allocation of Resources During the COVID-19 Pandemic and Other Health System Catastrophes. Annals of Internal Medicine. 17(3): 230-232.

Booth, R. (2020) 'Inquiry begins into blanket use in England of 'Do Not Resuscitate' orders' in The Guardian, $12^{\text {th }}$ October 2020, cited online on $14^{\text {th }}$ April 2021 at https://www.theguardian.com/world/2020/oct/12/inquiry-begins-into-blanket-use-in-england-ofcovid-do-not-resuscitate-orders

Briggs, D Ellis, A Lloyd, A \& Telford, L (2020) New hope or old futures in disguise? Neoliberalism, the Covid-19 pandemic and the possibility for social change. International Journal of Sociology and Social Policy. 40(9/10): 831-848.

Brown, E Kumar, S Rajjio, T Pollock, B \& Mulsant, B (2020) Anticipating and Mitigating the Impact of the COVID-19 Pandemic on Alzheimer's Disease and Related Dementias. American Journal of Geriatric Psychiatry. 28(7): 712-721.

Carter, P. (2016) Operational Productivity and Performance in English NHS Acute Hospitals: Unwarranted Variations. Independent Report for the Department of Health. Accessed from https://www.gov.uk/government/publications/productivity-in-nhs-hospitals

Costello, H., Cooper, C., Marston, L. and Livingston, G. (2020) Burnout in UK care home staff and its effect on staff turnover: MARQUE English national care home longitudinal study. Age and Ageing. 49(1) 74-81.

Cunningham, I. (2016) Non-profits and the 'hollowed out' state: The transformation of working conditions through personalizing social care services during an era of austerity. Work, Employment and Society. 30(4) 649-668.

Daly, M (2020) COVID-19 and care homes in England: What happened and why? Social Policy Administration. 54(7): 985-998.

Davis J Lister J Wrigley D (2015) NHS For Sale: Myths, Lies \& Deception. London: The Merlin Press Ltd.

Ferguson, I \& Lavalette, M (2013) Crisis, austerity and the future(s) of social work in the UK. Critical and Radical Social Work. 1(1): 95-110.

Fisher, D. (2021) 'You Never Know What You Could Walk Into': The Perceptions and Experiences of Adult Social Care Workers in Teesside, North-East England. Unpublished PhD Thesis, Teesside University.

Gordon, A., Goodman, C., Achterberg, W., Barker, R., Burns, E., Hanratty, B. et al. (2020) 'Commentary: COVID in Care Homes - Challenges and Dilemmas in Healthcare Delivery' in Age and Ageing, Vol 49 (5): 701-705. 
Harvey, D. (2010) The Enigma of Capital. London: Profile.

Heneghan C., and Jefferson T. (2020) 'Landmark Danish study finds no significant effect for face mask wearers' in The Spectator cited online at https://www.spectator.co.uk/article/do-masksstop-the-spread-of-covid-19-.

Jones, L \& Hameiri, S (2021) COVID-19 and the failure of the neoliberal regulatory state. Review of International Political Economy. 1-25.

Lintern, S. (2020) 'Coronavirus: care homes mentioned only twice in five months of Sage minutes

in The Independent $31^{\text {st }}$ May 2020 cited online at

https://www.independent.co.uk/news/health/coronavirus-sagemeetings-care-homesa9541321.html

McGilton, K., Escrig-Pinol, A., Gordon, A., Chu, C., Zuñiga, F., Sanchez, M. et al. (2020) 'Uncovering the devaluation of nursing home staff during Covid-19: Are we fuelling the next crisis? in JAMDA, Vol 21 (7): 962-965.

Nyashanu, M Pfende, F \& Ekpenyong, M (2020) Triggers of mental health problems among frontline healthcare workers during the COVID-19 pandemic in private care homes and domiciliary care agencies. Health and Social Care in the Community. 0(0): 1-7

Oliver, D (2020) Let's not forget care homes when covid-19 is over. British Medical Journal. 369: $1-2$.

Pollock, A.M. (2005) NHS Plc. London: Verso.

Power, A \& Hall, E (2018) Placing care in times of austerity. Social \& Cultural Geography. 19(3): 303-313.

Robbins, I Gordon, A Dyas, J Logan, P \& Gladman, J (2013) Explaining the barriers to and tensions in delivering effective health in UK care homes: a qualitative study. BMJ Open. 3: 1-9.

Saad-Filho, A (2020) From COVID-19 to the End of Neoliberalism. Critical Sociology

Schwab, K. \& Malleret, T. (2020) Covid 19: The Great Reset. Switzerland: World Economic Forum.

Shutes, I (2012) The Employment of Migrant Workers in Long-Term Care. Journal of Social Policy. 41(1): 43-59.

Slobodian, Q (2018) Globalists: The End of Empire and the Birth of Neoliberalism. Massachusetts: Harvard University Press.

Streeck, W (2016) How will capitalism end? London: Verso

Wood, H. and Skeggs, B. (2020) Clap for carers? For care gratitude to care justice.

European Journal of Cultural Studies. 23(4) 641-647.

https://doi.org/10.1177\%2F1367549420928362

Žižek, S (2021) Pandemic 2! Chronicles of a Time Lost. Cambridge: Polity Books. 